\title{
Evaluation of Pediatric Imaging Modalities Practices of Radiologists and Technologists: A Survey-Based Study
}

\author{
Abdulrahman Tajaldeen (1D', Osama A Mabrouk Kheiralla', Salem Saeed Alghamdi ${ }^{2}$, Haney Alsleem ', \\ Abdullah Al-Othman ${ }^{3}$, Elfatih Abuelhia $\mathbb{D}^{\prime}$, Rowa Aljondi ${ }^{2}$ \\ 'Department of Radiological Sciences, College of Applied Medical Science, Imam Abdulrahman Bin Faisal University, Dammam, Saudi Arabia; \\ ${ }^{2}$ Department of Applied Radiologic Technology, College of Applied Medical Sciences, University of Jeddah, Jeddah, Saudi Arabia; ${ }^{3}$ Radiology \\ Department, King Fahad University Hospital, Alkhobar, Saudi Arabia \\ Correspondence: Abdulrahman Tajaldeen, Email atajaldeen@gmail.com
}

\begin{abstract}
Introduction: Radiation protection for pediatric patients is the main concern in pediatric computed tomography (CT) due to their sensitive organs, such as the brain and the thyroid glands. Accordingly, an optimization of pediatric CT practices is vital to minimize the radiation dose for this population.

Aim: To assess the pediatric CT practices of radiologists and technologists in a CT unit.

Materials and Methods: The study was conducted among 26 hospitals, located in various regions in Saudi Arabia. A total of 200 hard copies of the questionnaire were distributed manually and were collected for analysis. In total, 117 completed surveys were gathered from technologies, while 49 were gathered from radiologists.

Results: In the case of infants with hydrocephalus, $65 \%$ of the radiologists ordered an ultrasound (US), $24 \%$ ordered a head CT scan, and $10 \%$ ordered a magnetic resonance imaging (MRI) and general X-ray for diagnosis. For pediatric patients complaining of persistent headache, $59 \%$ and $27 \%$ of the radiologists recommended CT and MRI, respectively, for diagnosis.

Conclusion: Most of the radiologists utilize CT head scan to diagnose persistent headache (by 59\%) and ventriculoperitoneal shunt (VPS) malfunction (by 41\%) in pediatric patients compared with the other modalities. The use of CT can increase the risk of later malignancy among pediatric patients due to radiation exposure. Alternative imaging modalities such as US and MRI (non-ionized radiation) should be considered to reduce the ionizing radiation hazards and optimize the current practices of radiologists. Most of the technologists follow radiation protection protocols in this study as $63 \%$ of the technologists used lead apron for pediatric patient's protection. Radiation awareness training for the technologists could improve the knowledge about the benefits of using lead apron and reduce the radiation risks in pediatric patients.
\end{abstract}

Keywords: computed tomography, pediatric, radiologists, radiation dose

\section{Introduction}

Recently, the number of requests by clinicians for pediatric computed tomography (CT) has increased, with such requests now representing about $11 \%$ of the total CT examinations that are conducted. ${ }^{1}$ This increase is likely related to the revolutionary CT technology that has been produced in recent years - particularly, helical CT and multislice CT, which provide a higher resolution and faster scanning in comparison to other imaging modalities. ${ }^{1-3}$ However, the calculated radiation dose required for a single CT examination ranges between $1.0 \mathrm{mSv}$ and $27 \mathrm{mSv}$, ${ }^{4}$ which is about $70 \%$ higher than the collective dose required by other diagnostic radiation examinations. ${ }^{4}$ Hence, when undergoing more complex procedures, such as computed tomography angiography (CTA), pediatric patients are exposed to a higher dose of radiation than they would be when undergoing examinations using other imaging modalities. ${ }^{5}$

In pediatric $\mathrm{CT}$, cancer effects are the primary concern because of the high radiation dose associated with CT imaging, the greater sensitivity to ionizing radiation within CT for pediatric patients, the patients' longer remaining life 
span, and the patients' small size. ${ }^{6}$ For pediatric patients undergoing CT, the risk of lifetime radiation-induced cancer and risk of mortality are higher compared with adults because of the higher lifetime risk per unit dose. ${ }^{7}$ Radiation protection for pediatric patients is the main concern in pediatric CT due to their sensitive organs, such as the brain and the thyroid glands. ${ }^{5}$ Accordingly, an optimization of pediatric CT practices is vital to minimize the radiation dose for this population.

The optimization of pediatric CT practices is vital to allow radiologists and technologists to ensure patient safety and reduce unnecessary doses to pediatric patients. As such, CT protocols and doses are constantly being evaluated and reevaluated. ${ }^{6,8,9}$ The International Atomic Energy Agency (IAEA) has released guidelines for performing pediatric CT, to help radiologists and technologists administer the lowest possible radiation dose to their patients. ${ }^{10,11}$ The IAEA's guidance includes performing only necessary pediatric CT examinations, replacing $\mathrm{CT}$ examinations with those requiring no radiation or a low radiation dose (eg, ultrasound [US] or magnetic resonance imaging [MRI]), utilizing protection devices (eg, lead protection), and checking each patient's records for previous examinations. A recent study at Saudi Arabia investigated the CT doses obtained from brain, chest and abdominal examinations collected from three local hospitals, indicated that the technologists provide a good practice and used radiation protection when scanning the patients. $^{5}$

In addition to the IAEA's guidance, several studies related to dose measurements in diagnostic and pediatric CT have been conducted in Saudi Arabia; ${ }^{10,11}$ however, no study has yet reviewed the evaluation practices of radiologists and technologists in pediatric CT in Saudi Arabia. ${ }^{12}$ Therefore, the aim of this study is to assess the pediatric CT practices of radiologists and technologists in a $\mathrm{CT}$ unit.

\section{Materials and Methods}

For data collection, an online questionnaire was created using the survey software QuestionPro. Two different surveys were designed, targeting radiologists and technologists, respectively, in pediatric CT. The questionnaire followed the recommendations of the IAEA for reducing pediatric CT doses. ${ }^{12}$

The questionnaires consisted of 3 sections and 15 questions: 13 were multiple choice, while 2 were open-ended questions. The first section requested the participants' employment information, including the name and region of the hospital at which they were employed, their job description, and, for the radiologists, their subspecialty (eg, neurology). No identifying information was requested. The second section related to the participants' general demographic information, such as their gender, age group, and years of experience as a radiologist or technologist. The third section included questions referring to the practices the participants followed when performing pediatric CT. All data were inserted and populated into a Microsoft Excel spreadsheet for analysis.

The study was conducted among 26 hospitals, located in various regions in Saudi Arabia. A total of 200 hard copies of the questionnaire were distributed manually and were collected for analysis. Emails containing a link to the questionnaire were also sent to the participants. Before distribution, the survey was edited to remove any typographic errors and to enhance the formatting. The participation period lasted two months, from April 15, 2021, to the end of July 2021. In total, 117 completed surveys were gathered from technologies, while 49 were gathered from radiologists.

\section{Inclusion Criteria}

Residency programs from R1-R4, the radiologists, consultants and technologists who worked at CT units.

\section{Exclusion Criteria}

Technologists who are not worked at CT units.

\section{Imaging Modalities Criteria Decision and Radiation Protection Protocols}

This study follows the protocols by American College of radiology (ACR $)^{13}$ for the radiologists and radiation protection in pediatric radiology by international atomic energy agency (IAEA) ${ }^{14}$ for the technologists as a criteria reference. The reader may refer to that papers for further information. 


\section{Statistical Analyses}

A descriptive cross-sectional design was adopted for this study. Descriptive statistics and graphical presentations of the survey data were expressed as frequencies and percentages. Two types of tests were used in this analysis:

\section{One-Sample Binomial Test (One-Tailed)}

This test was used to determine whether a certain percentage significantly exceeded a certain level, such as determining whether the percentage of participants who stated that they use US/MRI (from question 8 of the radiologist questionnaire) significantly exceeded $50 \%$.

\section{Pearson's Chi-Squared Test (One-Tailed)}

This test was used to determine whether the way in which answers were distributed for a certain question differed significantly among two categories of people (or more).

In all analyses, $\mathrm{p}<0.05$ was considered significant. All statistical analyses were performed using the software Statistical Package for Social Science (SPSS) Statistics, version 22.

\section{Results}

The results of this study were classified according to the diagnostic requests ordered by the radiologists for pediatric patients and by the current practices the technologists used to minimize the radiation doses they administered.

\section{Radiologists' Practices in Pediatric CT}

In this study, the requests by radiologists used to diagnose diseases among pediatric patients included head, neck, chest, and abdominal scans. In the case of infants with hydrocephalus, $65 \%$ of the radiologists ordered a US, $24 \%$ ordered a head CT scan, and 10\% ordered an MRI and general X-ray for diagnosis. For pediatric patients complaining of persistent headache, $59 \%$ and $27 \%$ of the radiologists recommended CT and MRI, respectively, for diagnosis. US was recommended by $59 \%$ of the radiologists to detect congenital torticollis, exceeding the percentages of those recommending other modalities including X-ray, CT, and MRI. For pediatric patients with suspected pleural effusion, the radiologists sought diagnosis using X-ray (73\%) and US (20\%) examinations (Table 1).

For children with signs of a choledochal cyst in abdominal imaging, most of the radiologists requested a US (90\%) for diagnosis, while 10\% recommended other modalities for diagnosis. For other abdominal diseases, the most common radiologist recommendation was a US, being recommended by $86 \%$ of radiologists for diagnosing biliary atresia and by $88 \%$ for diagnosing appendicitis or acute abdominal pain. Similarly, for intussusception and abdominal mass disease, US was most commonly recommended by the radiologists $(65 \%)$ as the first approach for diagnosis. For ventriculoperitoneal shunt (VPS) malfunction, the radiologists' protocols varied in relation to the first approach used for diagnosis: CT was the first approach of $41 \%$ of radiologists, followed by US (33\%), X-ray (16\%), and MRI (10\%) (Table 1).

When analyzing the radiologists' responses, the one-sample binomial test (one-tailed) showed that most of the presented percentages (except for those of 2 questions) related to the participants' recommended imaging modality significantly exceeded $50 \%$, with $\mathrm{p}$ values of $<0.05$. Exceptions to these significant results occurred in the questions related to diagnosing pediatric patients with suspected congenital torticollis and with features of VPS malfunction. Overall, most of the radiologists' answers indicated that they would utilize the recommended imaging modality for diagnosis. Pearson's chi-squared test (one-tailed) showed that the radiologists' responses did not vary significantly across experience levels. However, the percentage of radiologists who stated that they would select the recommended imaging modality was higher (ie, greater than $60 \%$ ) for those who had $>6$ years of experience compared with those who had $<6$ years of experience, for each question (Figure 1).

\section{Technologists' Practices in Pediatric CT}

When asked whether they would use the anterior-to-posterior (AP) scout view, lateral scout view, or both scout views for pediatric head CT scans, $23.93 \%$ of the technologists opted for the AP view, $34.19 \%$ for the lateral view, and $41.88 \%$ for both. About $71.8 \%$ of the CT technologists indicated that they would employ patient sedation for those under the age of 5 
Table I Radiologists' Responses to the Survey Evaluating Practices in Pediatric CT

\begin{tabular}{|c|c|c|c|c|c|c|c|}
\hline \multicolumn{2}{|c|}{$\begin{array}{l}\text { Questions: Which of the Following } \\
\text { Imaging Modalities is the First Choice } \\
\text { of Examination for: }\end{array}$} & \multirow{2}{*}{$\begin{array}{r}\text { X-Ray } \\
\text { I (2) }\end{array}$} & \multirow{2}{*}{\begin{tabular}{|c|} 
US \\
$32(65)$
\end{tabular}} & \multirow{2}{*}{\begin{tabular}{|c|} 
CT \\
$12(24)$
\end{tabular}} & \multirow{2}{*}{\begin{tabular}{|l} 
MRI \\
$4(8)$
\end{tabular}} & \multirow{2}{*}{$\begin{array}{c}\text { Total } \\
49(100)\end{array}$} & \multirow{2}{*}{$\begin{array}{c}\begin{array}{c}\text { Significance } \\
\text { (p value*) for } \\
\text { Exceeding } \\
\mathbf{5 0} \%\end{array} \\
0.001\end{array}$} \\
\hline $\begin{array}{l}\text { Head } \\
\text { Scan }\end{array}$ & $\begin{array}{l}\text { QI: An infant with } \\
\text { hydrocephalus? }\end{array}$ & & & & & & \\
\hline & $\begin{array}{l}\text { Q2: A child with } \\
\text { persistent headache? }\end{array}$ & $4(8)$ & $3(6)$ & $29(59)$ & $13(27)$ & $49(100)$ & 0.000 \\
\hline & $\begin{array}{l}\text { Q3: A child with features } \\
\text { of VPS malfunction? }\end{array}$ & $8(16)$ & $16(33)$ & $20(4 I)$ & $5(10)$ & $49(100)$ & 0.443 \\
\hline Neck Scan & $\begin{array}{l}\text { Q4: An infant with } \\
\text { congenital torticollis? }\end{array}$ & $6(12)$ & $29(59)$ & $7(14)$ & $7(14)$ & $49(100)$ & 0.156 \\
\hline $\begin{array}{l}\text { Chest } \\
\text { Scan }\end{array}$ & $\begin{array}{l}\text { Q5: A child with signs of } \\
\text { pleural effusion? }\end{array}$ & $36(73)$ & $10(20)$ & $3(6)$ & $0(0)$ & $49(100)$ & 0.000 \\
\hline \multirow[t]{5}{*}{$\begin{array}{l}\text { Abdomen } \\
\text { Scan }\end{array}$} & $\begin{array}{l}\text { Q6: A child with signs of } \\
\text { a choledochal cyst? }\end{array}$ & $2(4)$ & $44(90)$ & $2(4)$ & I (2) & $49(100)$ & 0.000 \\
\hline & $\begin{array}{l}\text { Q7: A child with signs of } \\
\text { biliary atresia? }\end{array}$ & I (2) & $42(86)$ & $2(4)$ & $4(8)$ & $49(100)$ & 0.000 \\
\hline & $\begin{array}{l}\text { Q8: A child with } \\
\text { symptoms of } \\
\text { appendicitis (eg, acute } \\
\text { abdominal pain)? }\end{array}$ & $3(6)$ & $43(88)$ & $3(6)$ & $0(0)$ & $49(100)$ & 0.000 \\
\hline & $\begin{array}{l}\text { Q9: A child with signs of } \\
\text { intussusception? }\end{array}$ & $10(20)$ & $32(65)$ & $4(8)$ & $3(6)$ & $49(100)$ & 0.030 \\
\hline & $\begin{array}{l}\text { QI0: A child with } \\
\text { features of an abdominal } \\
\text { mass? }\end{array}$ & $8(16)$ & $32(65)$ & $8(16)$ & I (2) & $49(100)$ & 0.030 \\
\hline
\end{tabular}

Notes: Data are expressed as number (percentage); *A one-sample binomial test was used.

Abbreviations: CT, computed tomography; MRI, magnetic resonance imaging; US, ultrasound; VPS, ventriculoperitoneal shunt.

years. As part of the radiation protection protocol, $63.25 \%$ of the technologists agreed that using a lead apron or radiation protection method to protect pediatric patients in CT departments is necessary (Table 1). However, $42.74 \%$ responded that they had no knowledge of bismuth shield application during pediatric CT scanning, while $34.19 \%$ disagreed that the application of a bismuth shield decreases the radiation dose to pediatric patients. About $67.52 \%$ of the technologists responded that they keep records of pediatric patients' doses in their CT Departments; these records are reviewed by the radiologists and technologists weekly $(22.22 \%$ of radiologists and $28.21 \%$ of technologists) or yearly $(35.90 \%$ of radiologists and $29.91 \%$ of technologists). By contrast, $27.35 \%$ of radiologists and $24.79 \%$ of technologists stated that they perform no reviews of patient dose records at any time in the year (Table 2).

The one-sample binomial test (one-tailed) showed that most of the technologists' responses (except for the responses to the first question) reflect the recommended practices in CT departments, significantly exceeding $50 \%$ (with p values $<$ 0.05). Pearson's chi-squared test (one-tailed) showed that the technologists' responses did not vary significantly across experience levels. However, the percentage of technologists who stated that they would follow the recommended practices was higher (ie, greater than 60\%) for those who had $>6$ years of experience compared with those who had $<6$ years of experience, for each question (Figure 2). 


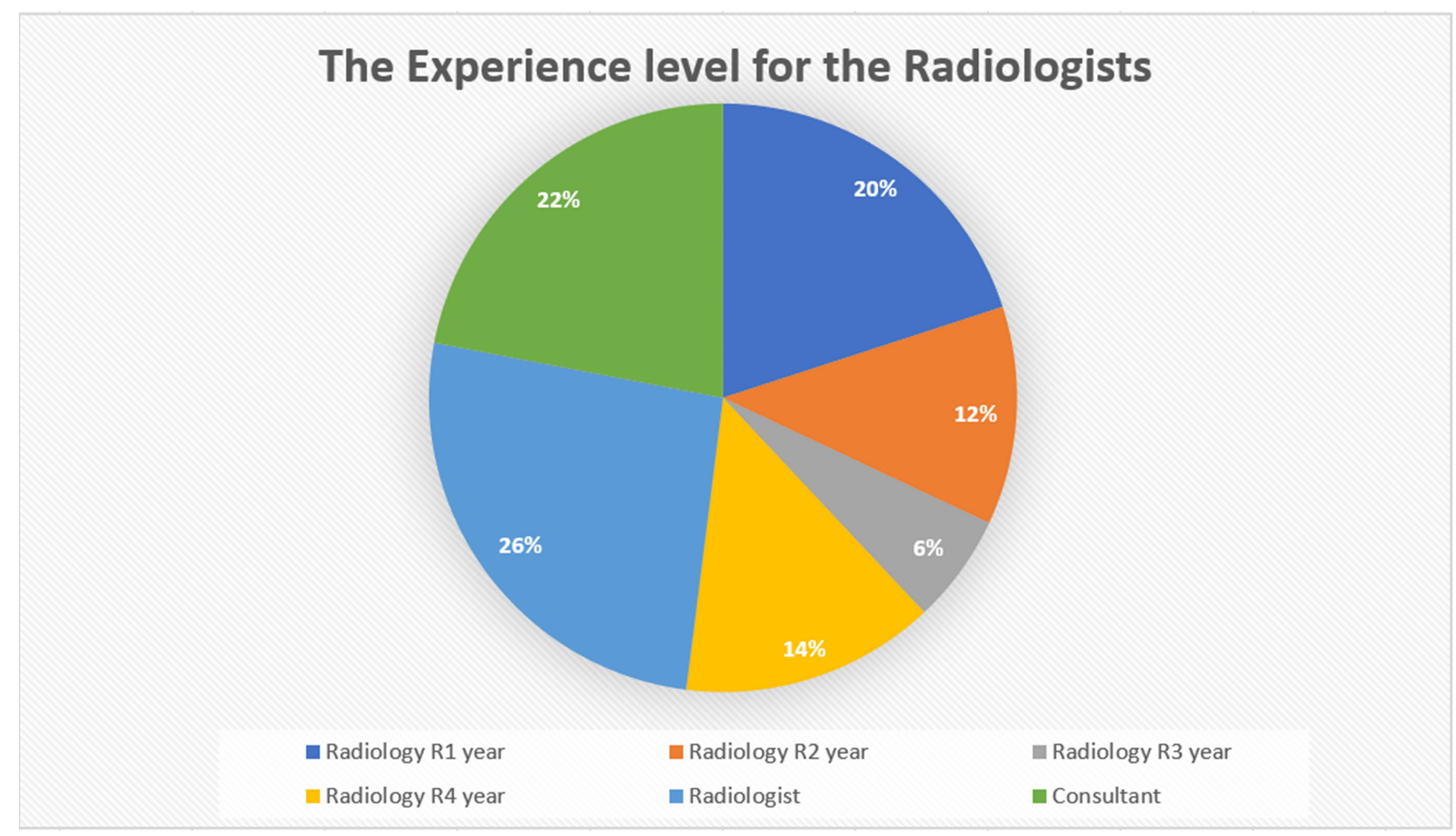

Figure I The experience levels of the participants in the survey, including those in radiology years RI-R4, radiologists, and consultants.

\section{Discussion}

The role of radiologists and technologists is vital to decreasing the potential radiation hazards in pediatric CT. For example, when requesting additional examinations of pediatric patients, radiologists can avoid exposing patients to unnecessary ionizing radiation by ensuring that they select the recommended image modality, which will provide a good diagnosis and eliminate unnecessary radiation doses. The results of this study show that radiologists and technologists do follow good practices in pediatric CT.

However, the radiologists' responses related to head scans (Q1-Q3) indicated that they tend to choose imaging modalities that are not recommended, such as CT scans, over other modalities for pediatric cases. For diagnosing hydrocephalus via a head scan, the participants selected US as the first approach, followed by CT. Utilizing CT for initial and subsequent assessments of pediatric hydrocephalus may not offer sufficient anatomical details to aid in neurosurgical management techniques, such as endoscopic third ventriculostomy (ETV) procedures. ${ }^{15,16}$ Moreover, evaluating children with hydrocephalus requires multiple investigations and a long-term follow-up period to monitor shunt function. Despite that, low-dose CT protocols have been used in the evaluation of hydrocephalus to decrease dose accumulation, harmful effects on the developing brain, and related lifetime oncologic risks that come with repeated exposure due to multiple examinations. $^{15,16}$

Radiologic evaluation is essential in the diagnosis of VPS malfunction. The evaluation begins with a plain radiograph to ensure the structural integrity of the shunt catheter. A pediatric head CT scan is often used to assess the increase in ventricular size, an indication of VPS malfunction. ${ }^{17}$ An alternative method for achieving this is MRI, which can provide acceptable images for diagnosing VPS malfunction in pediatric patients. ${ }^{18}$ Margaret et al suggested that MRI scans should be used more often in the diagnosis of VPS malfunction, as they do not require radiation exposure, unlike CT scans. ${ }^{18}$ Moreover, if a radiologist must request a CT scan, it is recommended to use a limited 4-slice CT head scan, as this reduces the effective dose to $87 \%$ of the dose required in a full CT scan. ${ }^{17}$

According to Sarma and Poussaint, non-contrast MRI and CT scans are recommended in diagnosing persistent headache in pediatric patients. ${ }^{19}$ MRI is the initial modality that should be used in evaluating most types of pediatric headache because of its superior tissue contrast resolution, which allows for better tissue characterization and the 
Table 2 Technologists' Responses to the Survey Evaluating Practices in Pediatric CT

\begin{tabular}{|c|c|c|c|c|c|c|}
\hline Questions & \multicolumn{4}{|c|}{ Frequency } & \multirow[t]{2}{*}{ Total } & \multirow{2}{*}{$\begin{array}{c}\text { Significance } \\
\text { (p value*) } \\
\text { for } \\
\text { Exceeding } \\
50 \%\end{array}$} \\
\hline \multirow{2}{*}{$\begin{array}{l}\text { QI: In a head CT scan for pediatric } \\
\text { patients, the scout image in your CT } \\
\text { department is performed in }\end{array}$} & AP & Lateral & Both & & & \\
\hline & $28(23.93)$ & $40(34.19)$ & $49(41.88)$ & & $117(100)$ & 1.000 \\
\hline \multirow{2}{*}{$\begin{array}{l}\text { Q2: In your CT department, patient } \\
\text { sedation is used for the following age } \\
\text { group of pediatric patients }\end{array}$} & < I year & I-5 years & $5-10$ years & $10-15$ years & & \\
\hline & $33(28.21)$ & 51 (43.59) & $24(20.5 I)$ & 9 (7.69) & $117(100)$ & 0.001 \\
\hline \multirow{2}{*}{$\begin{array}{l}\text { Q3: A lead apron or radiation } \\
\text { protection method is used by } \\
\text { radiographers or radiologic } \\
\text { technologists during } C T \text { pediatric } \\
\text { protocols }\end{array}$} & $\begin{array}{l}\text { Strongly } \\
\text { Agree }\end{array}$ & Agree & Disagree & $\begin{array}{l}\text { Strongly } \\
\text { Disagree }\end{array}$ & & \\
\hline & $44(37.6 I)$ & $30(25.64)$ & $25(21.37)$ & $18(15.38)$ & $117(100)$ & 0.001 \\
\hline \multirow{2}{*}{$\begin{array}{l}\text { Q4: I have knowledge about bismuth } \\
\text { shield application during } C T \text { pediatric } \\
\text { protocols }\end{array}$} & $\begin{array}{l}\text { Strongly } \\
\text { Agree }\end{array}$ & Agree & Disagree & $\begin{array}{l}\text { Strongly } \\
\text { Disagree }\end{array}$ & & \\
\hline & $31(26.50)$ & $36(30.77)$ & $29(24.79)$ & $21(17.95)$ & II7 (100) & 0.041 \\
\hline \multirow{2}{*}{$\begin{array}{l}\text { Q5: Bismuth shield application can } \\
\text { reduce the dose to the breast or eye of } \\
\text { pediatric patients }\end{array}$} & $\begin{array}{l}\text { Strongly } \\
\text { Agree }\end{array}$ & Agree & Disagree & $\begin{array}{l}\text { Strongly } \\
\text { Disagree }\end{array}$ & & \\
\hline & $30(25.64)$ & $47(40.17)$ & $23(19.66)$ & $17(14.53)$ & $117(100)$ & 0.000 \\
\hline \multirow{2}{*}{$\begin{array}{l}\text { Q6: Our CT department keeps the } \\
\text { records of pediatric patients' doses }\end{array}$} & Yes & No & & & & \\
\hline & $79(67.52)$ & 38 (32.48) & & & $117(100)$ & 0.000 \\
\hline \multirow{2}{*}{$\begin{array}{l}\text { Q7: The radiologists review the } \\
\text { patients' dose records }\end{array}$} & Weekly & Monthly & Yearly & None & & \\
\hline & $26(22.22)$ & $42(35.90)$ & $17(14.53)$ & $32(27.35)$ & $117(100)$ & 0.024 \\
\hline \multirow{2}{*}{$\begin{array}{l}\text { Q8: The radiographers/ radiologic } \\
\text { technologists review the patients' dose } \\
\text { records }\end{array}$} & Weekly & Monthly & Yearly & None & & \\
\hline & $33(28.21)$ & $35(29.91)$ & $20(17.09)$ & $29(24.79)$ & $117(100)$ & 0.024 \\
\hline
\end{tabular}

Notes: Data are expressed as number (percentage); *A one-sample binomial test was used.

Abbreviations: AP, anterior-to-posterior; $\mathrm{CT}$, computed tomography.

detection of small lesions. ${ }^{19}$ Unlike CT, MRI utilizes electromagnetic radiation, which confers no carcinogenic risks. ${ }^{20,21}$ The results of the current study show that, in general, the radiologists are not following these recommendations. Most of the radiologists selected CT as first choice for diagnosing persistent headache, followed by MRI. This is likely due to the speed of the scan; because CT scans are relatively quick, there is less need for pediatric sedation. CT is also clinically useful for unstable patients or patients with implanted devices such as cochlear implants. ${ }^{19,22}$

A retrospective study by Boyko et al investigated 683 infant patients who were referred for the management of torticollis. They recommended that neither radiography, CT, nor MRI are necessary for evaluating torticollis in infants; a clinical examination alone is sufficient for diagnosis. ${ }^{23}$ Applying this study's results in the diagnosis protocol used by radiologists could help to limit the exposure of pediatric patients to ionizing radiation, as 13 out of 49 responses in our study (about 27\%) suggested using X-ray and CT scans in the diagnosis process. 


\section{The Experience level for the technologists}

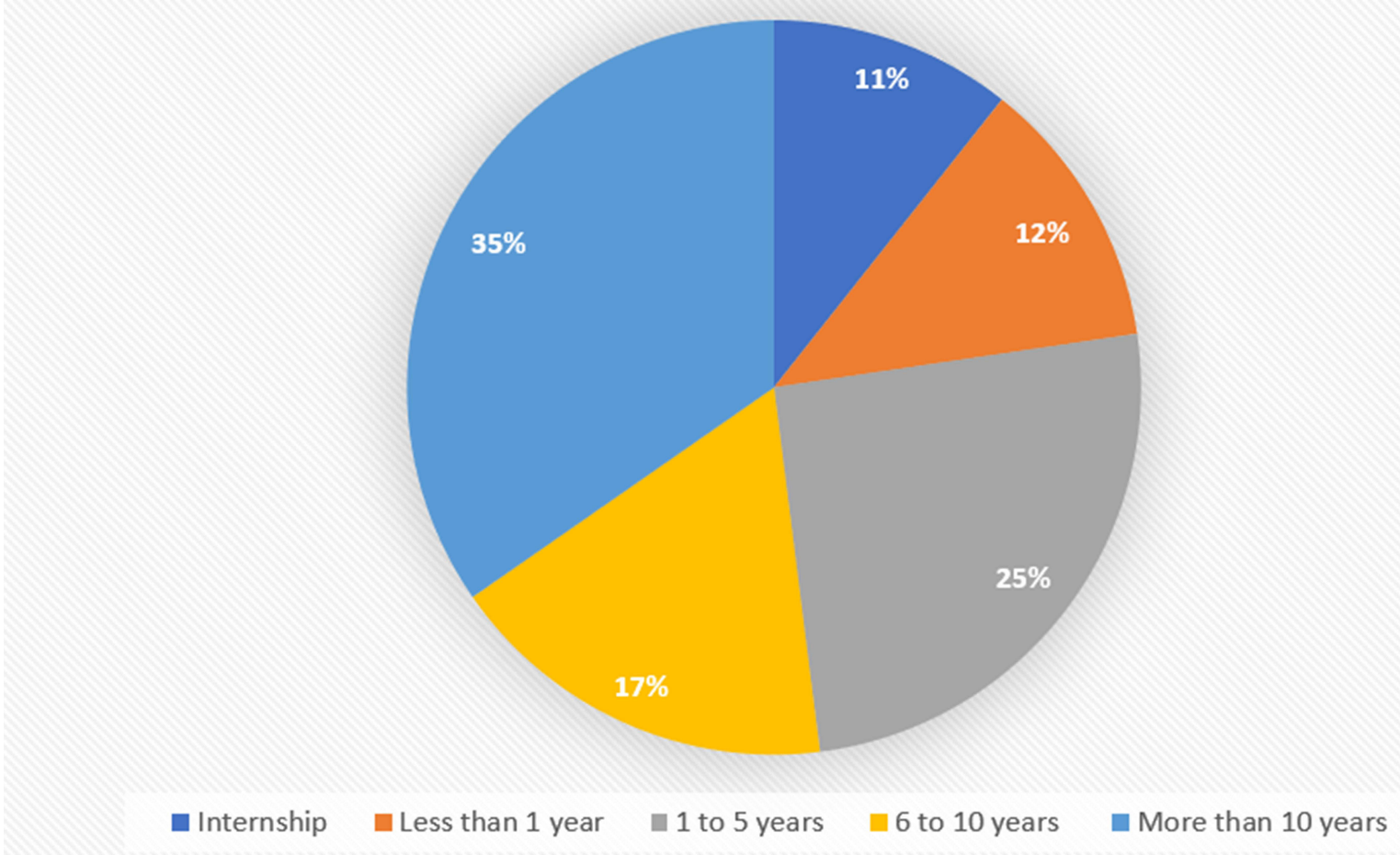

Figure 2 The experience levels of the technologists who participated in the survey, including those in their internship year and those with less than I year to more than 10 years of experience.

In children, a chest radiograph can indicate the presence of parapneumonic collection, and it is therefore considered the main tool for evaluating the appropriate treatment response. Following the treatment of the parapneumonic effusion (PPE), US is used to confirm the presence of pleural fluid. CT is a useful tool when these less invasive modalities are inconclusive, but it should not be considered a routine investigation due to the associated radiation exposure. ${ }^{24,25}$

In relation to abdominal scans, most of the radiologists' responses in this study concurred with the literature that US should be the first approach used for diagnosing a choledochal cyst, biliary atresia, intussusception, and an abdominal mass. ${ }^{26-35}$ For pediatric patients with suspected appendicitis, the first approach should also be US. ${ }^{36}$ If a radiology report is inconclusive, a US can be followed up with a CT scan. A CT scan can also be performed to further assess the findings of a US or if the pediatric patient has a body mass index of $>30 .{ }^{36}$ However, six radiologists in the current study stated that they would select an X-ray and $\mathrm{CT}$ as their first choices for diagnosing appendicitis, which may result in unnecessary radiation doses being administered to pediatric patients. In addition, $4 \%$ to $16 \%$ of the radiologists stated that they would utilize a CT scan instead of a US to diagnose abdominal pathologies. Changing these trends in diagnostic procedures could decrease the exposure of pediatric patients to ionizing radiation.

The results from the current study concurred with the results from D. Kostova-Lefterova and J. Vassileva. ${ }^{3}$ For both studies, the reference criteria was based on American college of radiology, ${ }^{13}$ and the trends for the first approach of examination for hydrocephalus, VPS malfunction, pleural effusion and symptoms of appendicitis were similar (Table 3). However, the Bulgarian study utilized non-ionized radiation imaging modalities such as MRI and US as second choice for pediatric imaging (Table 3).

In CT examinations, the scout view is utilized in children with suspected shunt malfunction caused by hydrocephalus, and it results in no additional radiation exposure. ${ }^{37}$ According to previous studies, the scout view is used for the correct planning of CT images; clinically, abnormal findings are recognizable only in scout view in about $20 \%$ of cases. ${ }^{37,38}$ Another 
Table 3 A Comparison Between the Radiologists' Responses to the Survey Evaluating Practices in Pediatric Imaging Modalities

\begin{tabular}{|c|c|c|c|c|c|c|}
\hline \multicolumn{3}{|c|}{ Questions: Which of the Following Imaging Modalities is the First Choice of Examination for: } & \multirow{2}{*}{$\frac{\text { X-Ray }}{4}$} & \multirow{2}{*}{$\frac{\text { US }}{\mathrm{I}}$} & \multirow{2}{*}{$\frac{\text { CT }}{2}$} & \multirow{2}{*}{$\frac{\text { MRI }}{3}$} \\
\hline Head Scan & An infant with hydrocephalus? & The current study & & & & \\
\hline & & $\begin{array}{l}\text { D. Kostova-Lefterova and } \\
\text { J. Vassileva }{ }^{3}\end{array}$ & - & I & 3 & 2 \\
\hline & A child with persistent headache? & The current study & 3 & 4 & 1 & 2 \\
\hline & & $\begin{array}{l}\text { D. Kostova-Lefterova and } \\
\text { J. Vassileva }{ }^{3}\end{array}$ & - & 3 & 2 & 1 \\
\hline & A child with features of VPS malfunction? & The current study & 3 & 2 & 1 & 4 \\
\hline & & $\begin{array}{l}\text { D. Kostova-Lefterova and } \\
\text { J. Vassileva }{ }^{3}\end{array}$ & - & - & 1 & 2 \\
\hline \multirow[t]{2}{*}{ Neck Scan } & \multirow[t]{2}{*}{ An infant with congenital torticollis? } & The current study & 3 & I & 2 & 2 \\
\hline & & $\begin{array}{l}\text { D. Kostova-Lefterova and } \\
\text { J. Vassileva }{ }^{3}\end{array}$ & 2 & 3 & 4 & 1 \\
\hline \multirow[t]{2}{*}{ Chest Scan } & \multirow[t]{2}{*}{ A child with signs of pleural effusion? } & The current study & 1 & 2 & 3 & 0 \\
\hline & & $\begin{array}{l}\text { D. Kostova-Lefterova and } \\
\text { J. Vassileva }{ }^{3}\end{array}$ & I & 2 & - & - \\
\hline \multirow{2}{*}{$\begin{array}{l}\text { Abdomen } \\
\text { scan }\end{array}$} & \multirow{2}{*}{$\begin{array}{l}\text { A child with symptoms of appendicitis (eg, acute } \\
\text { abdominal pain)? }\end{array}$} & The current study & 2 & I & 2 & 0 \\
\hline & & $\begin{array}{l}\text { D. Kostova-Lefterova and } \\
\text { J. Vassileva }{ }^{3}\end{array}$ & 2 & I & - & - \\
\hline
\end{tabular}

Notes: Index I: indicate the first choice of the examination (the highest radiologist's responses), while index 4: the least preferable choice for the examination (the lowest radiologist's responses) based on the radiologist's responses from both studies.

Abbreviations: CT, computed tomography; MRI, magnetic resonance imaging; US, ultrasound; VPS, ventriculoperitoneal shunt.

advantage of scout view is that it can provide information about pathologies occurring outside the region covered by crosssectional imaging, which is especially useful in the diagnostic follow up of suspected shunt malfunction. ${ }^{37,39,40}$ The current study shows that the majority of the technologists surveyed (42\%) are applying the scout view in both the AP and lateral view, broadening their field of view coverage and the clinical benefits. However, many studies suggest that the lateral scout view alone is sufficient to obtain these advantages and reduce the radiation exposure. ${ }^{37,39,40}$

Pediatric sedation is required during a CT examination for infants and children younger than five years old to ensure that the image obtained is of good diagnostic quality and to decrease the presence of motion artefacts. ${ }^{41}$ The results of this study demonstrate that the technologists follow the same method across CT departments for pediatric cases. However, adverse events following sedation can occur even when a pediatric anesthesia team is present. ${ }^{42}$ For example, pediatric exposure to general anesthesia can have a negative long-term effect on cognitive development. ${ }^{43,44}$ As such, it is preferable to utilize CT scanning techniques that are fast enough that motion artefacts are not a problem, that allow patients to be awake during scanning, that allow free breathing during scanning. Currently, two techniques allow these things: 1) the use of an ultra-high table pitch (pitch > 3) and 2) the use of wide area detectors. ${ }^{41}$

CT doses for pediatric patients can be decreased using bismuth organ shields, particularly for anterior organs. These shields are considered to mitigate the radiation risks to specific radiosensitive organs. The shields are made of bismuthimpregnated latex, with each shield containing 0.85 to $3.4 \mathrm{~g} / \mathrm{cm}$ of bismuth. They are designed to be placed over the organ of interest (eg, the gonads, thyroids, breasts, or eyes) during a CT scan. ${ }^{45-48}$ In this study, most of the technologists indicated that they had a good level of knowledge about bismuth shield applications for pediatric patients. This knowledge is important because, according to Samei, the improper use of a bismuth shield can cause the patient to be overexposed to radiation. ${ }^{49}$ Moreover, the quantitative accuracy of the CT number can be affected by the shields, especially in the area closest to the shield. Finally, when a shield is Applied, there is a possibility that some of the dose could be wasted. ${ }^{49}$ 
According to the participants in this study, most of the patients' dose records are kept by the CT departments and checked monthly by the radiologists and technologists. Because some of the hospitals participating in this study are not connected to the central system for dose records, $\leq 38 \%$ of the of the survey participants indicated that they did not keep patients' dose records.

Based on findings from radiologists and technologists, this study provides recommendations for the use of alternative, safer imaging modalities, such as non-ionized radiation US and MRI, instead of CT to reduce the radiation dose given to pediatric patients. Following this survey, further investigation of the actual dose records of pediatric patients who have undergone common pediatric $\mathrm{CT}$ is required.

\section{Conclusion}

Most of the radiologists utilize CT head scan to diagnose persistent headache (by 59\%) and VPS malfunction (by 41\%) in pediatric patients compared with the other modalities. The use of CT can increase the risk of later malignancy among pediatric patients due to radiation exposure. Alternative imaging modalities such as US and MRI (non-ionized radiation) should be considered to reduce the ionizing radiation hazards and optimize the current practices of radiologists. Most of the technologists follow radiation protection protocols in this study as $63 \%$ of the technologists used lead apron for pediatric patient's protection. Radiation awareness training for the technologists could improve the knowledge about the benefits of using lead apron and reduce the radiation risks in pediatric patients.

\section{Ethics Approval}

This study was approved by IRB committee at Imam Abdulrahman bin Faisal university, reference number is: IRB-202203-036.

\section{Consent}

The informed consent was obtained from the study participants. All participants agreed to contribute at the research.

\section{Funding}

This research received no specific grant from any funding agency in the public, commercial, or not-for-profit sectors.

\section{Disclosure}

The authors report no conflicts of interest for this work and declare no conflict of interest in preparing this article.

\section{References}

1. Bernier M-O, Baysson H, Pearce MS, et al. Cohort profile: the EPI-CT study: a European pooled epidemiological study to quantify the risk of radiation-induced cancer from paediatric CT. Int J Epidemiol. 2019;48:379-381g. doi:10.1093/ije/dyy231

2. Nagel HD. CT parameters that influence the radiation dose. In: Radiation Dose from Adult and Pediatric Multidetector Computed Tomography. Springer. 2007:51-79.

3. Kostova-Lefterova D, Vassileva J. Survey of practice in paediatric computed tomography. Radiat Prot Dosimetry. 2011;147:156-159. doi:10.1093/ $\mathrm{rpd} / \mathrm{ncr} 327$

4. Bernier M, Rehel J, Brisse $\mathrm{H}$, et al. Radiation exposure from $\mathrm{CT}$ in early childhood: a French large-scale multicentre study. $B r J$ Radiol. 2012;85:53-60. doi:10.1259/bjr/90758403

5. Alkhorayef M. Survey of paediatric imaging exposure from computed tomography examinations. Radiation Phys Chem. $2020 ; 167: 108261$. doi:10.1016/j.radphyschem.2019.04.011

6. ACR-AAPM. Practice parameter for diagnostic reference levels and achievable doses in Medical X-ray imaging. Am Coll Radiol Reston. 2014;1:74.

7. Brenner DJ, Elliston CD, Hall EJ, et al. Estimated risks of radiation-induced fatal cancer from pediatric CT. Am j Roentgenol. 2001;176:289-296. doi:10.2214/ajr.176.2.1760289

8. Huda W, Mettler FA. Volume CT dose index and dose-length product displayed during CT: what good are they? Radiology. 2011;258:236-242. doi:10.1148/radiol.10100297

9. Kharbanda AB, Krause E, Lu Y, et al. Analysis of radiation dose to pediatric patients during computed tomography examinations. Acad Emerg Med. 2015;22(6):670-675. doi:10.1111/acem.12689

10. Alkhorayef M, Hamza Y, Sulieman A, et al. Effective dose and radiation risk estimation in certain paediatric renal imaging procedures. Radiation Phys Chem. 2019;154:64-68. doi:10.1016/j.radphyschem.2018.06.016

11. Sulieman A, Mahmoud M, Serhan O, et al. CT examination effective doses in Saudi Arabia. Appl Radiat Isot. 2018;141:261-265. doi:10.1016/j. apradiso.2018.07.011 
12. International Atomic Energy Agency. Radiation Protection in Paediatric Radiology. Vienna: International Atomic Energy Agency; 2013.

13. ACR ACoR. Available from: https://www.acr.org/Clinical-Resources/ACR-Appropriateness-Criteria. Accessed February $23,2022$.

14. Rehani M. Radiation Protection in Paediatric Radiology. International Atomic Energy Agency; 2012.

15. Krishnan P, Raybaud C, Palasamudram S, et al. Neuroimaging in pediatric hydrocephalus. Indian J Pediatrics. 2019;2:1-9.

16. Gibbs WN, Tanenbaum LN. Imaging of hydrocephalus. Appl Radiol. 2018;47:5-13.

17. Park DB, Hill JG, Thacker PG, et al. The role of limited head computed tomography in the evaluation of pediatric ventriculoperitoneal shunt malfunction. Pediatr Emerg Care. 2016;32:585-589. doi:10.1097/PEC.0000000000000760

18. Trost MJ, Robison N, Coffey D, et al. Changing trends in brain imaging technique for pediatric patients with ventriculoperitoneal shunts. Pediatr Neurosurg. 2018;53:116-120. doi:10.1159/000485923

19. Sarma A, Poussaint TY. Indications and Imaging Modality of Choice in Pediatric Headache. Neuroimaging Clinics. 2019;29:271-289. doi:10.1016/ j.nic.2019.01.007

20. Goske MJ, Applegate KE, Boylan J, et al. The Image Gently campaign: working together to change practice. Am J Roentgenol. 2008;190:273-274. doi:10.2214/AJR.07.3526

21. Scheinfeld MH, Moon J-Y, Fagan MJ, et al. MRI usage in a pediatric emergency department: an analysis of usage and usage trends over 5 years. Pediatr Radiol. 2017;47:327-332. doi:10.1007/s00247-016-3764-y

22. Patel SK, Yuan W, Mangano FT. Advanced neuroimaging techniques in pediatric hydrocephalus. Pediatr Neurosurg. 2017;52:436-445. doi:10.1159/000454717

23. Boyko N, Eppinger MA, Straka-DeMarco D, et al. Imaging of congenital torticollis in infants: a retrospective study of an institutional protocol. J Neurosurg Pediatr. 2017;20:191-195. doi:10.3171/2017.3.PEDS16277

24. King S, Thomson A. Radiological perspectives in empyema: childhood respiratory infections. Br Med Bull. 2002;61:203-214. doi:10.1093/bmb/ 61.1.203

25. Calder A, Owens CM. Imaging of parapneumonic pleural effusions and empyema in children. Pediatr Radiol. 2009;39:527-537. doi:10.1007/ s00247-008-1133-1

26. Murphy AJ, Axt JR, Crapp SJ, et al. Concordance of imaging modalities and cost minimization in the diagnosis of pediatric choledochal cysts. Pediatr Surg Int. 2012;28:615-621. doi:10.1007/s00383-012-3089-3

27. Saito T, Terui K, Mitsunaga T, et al. Significance of imaging modalities for preoperative evaluation of the pancreaticobiliary system in surgery for pediatric choledochal cyst. J Hepato-Biliary-Pancreatic Sci. 2016;23:347-352. doi:10.1002/jhbp.347

28. Napolitano M, Franchi-Abella S, Damasio MB, et al. Practical approach to imaging diagnosis of biliary atresia, Part 1: prenatal ultrasound and magnetic resonance imaging, and postnatal ultrasound. Pediatr Radiol. 2021;51:314-331. doi:10.1007/s00247-020-04840-9

29. Kolar M, Pilkington M, Winthrop A, et al. Diagnosis and treatment of childhood intussusception from 1997 to 2016: a population-based study. J Pediatr Surg. 2020;55:1562-1569. doi:10.1016/j.jpedsurg.2020.01.049

30. Otero HJ, White AM, Khwaja AB, et al. Imaging intussusception in children's hospitals in the United States: trends, outcomes, and costs. $J$ Am Coll Radiol. 2019;16:1636-1644. doi:10.1016/j.jacr.2019.04.011

31. Binkovitz LA, Kolbe AB, Orth RC, et al. Pediatric ileocolic intussusception: new observations and unexpected implications. Pediatr Radiol. 2019;49:76-81. doi:10.1007/s00247-018-4259-9

32. Chew R, Ditchfield M, Paul E, et al. Comparison of safety and efficacy of image-guided enema reduction techniques for paediatric intussusception: a review of the literature. J Med Imaging Radiat Oncol. 2017;61:711-717. doi:10.1111/1754-9485.12601

33. Mandeville K, Chien M, Willyerd FA, et al. Intussusception: clinical presentations and imaging characteristics. Pediatr Emerg Care. 2012;28:842-844. doi:10.1097/PEC.0b013e318267a75e

34. Crane GL, Hernanz-Schulman M. Current imaging assessment of congenital abdominal masses in pediatric patients. Semin Roentgenol. 2012;32-44. doi:10.1053/j.ro.2011.07.004

35. Hanafy AK, Mujtaba B, Roman-Colon AM, et al. Imaging features of adrenal gland masses in the pediatric population. Abdominal Radiol. 2019;44:1-18. doi:10.1007/s00261-018-1673-2

36. Jones RE, Gee KM, Preston SC, et al. Diagnostic utilization and accuracy of pediatric appendicitis imaging at adult and pediatric centers. $J$ Surg Res. 2019;240:97-103. doi:10.1016/j.jss.2019.02.047

37. Orman G, Bosemani T, Tekes A, et al. Scout view in pediatric CT neuroradiological evaluation: do not underestimate! Childs Nerv Syst. 2014;30 (2):307-311. doi:10.1007/s00381-013-2288-0

38. Sener RN, Ripeckyj G, Otto P, et al. Recognition of abnormalities on computed scout images in CT examinations of the head and spine. Neuroradiology. 1993;35:229-231. doi:10.1007/BF00588503

39. Sivaganesan A, Krishnamurthy R, Sahni D, et al. Neuroimaging of ventriculoperitoneal shunt complications in children. Pediatr Radiol. 2012;42:1029-1046. doi:10.1007/s00247-012-2410-6

40. Brook OR, Guralnik L, Engel A. CT scout view as an essential part of CT reading. Australas Radiol. 2007;51:211-217. doi:10.1111/j.14401673.2007.01715.x

41. Gottumukkala RV, Kalra MK, Tabari A, et al. Advanced CT Techniques for Decreasing Radiation Dose, Reducing Sedation Requirements, and Optimizing Image Quality in Children. Radiographics. 2019;39(3):709-726. doi:10.1148/rg.2019180082

42. Slovis TL. Sedation and anesthesia issues in pediatric imaging. Pediatr Radiol. 2011;41:514-516. doi:10.1007/s00247-011-2115-2

43. Wilder RT, Flick RP, Sprung J, et al. Early Exposure to Anesthesia and Learning Disabilities in a Population-based Birth Cohort. Anesthesiology. 2009;110:796-804. doi:10.1097/01.anes.0000344728.34332.5d

44. Rappaport BA, Suresh S, Hertz S, et al. Anesthetic Neurotoxicity — clinical Implications of Animal Models. N Engl J Med. 2015;372:796-797. doi:10.1056/NEJMp1414786

45. Mukundan JS, Wang PI, Frush DP, et al. MOSFET dosimetry for radiation dose assessment of bismuth shielding of the eye in children. Am j Roentgenol. 2007;188:1648-1650. doi:10.2214/AJR.06.1146

46. Coursey C, Frush DP, Yoshizumi T, et al. Pediatric chest MDCT using tube current modulation: effect on radiation dose with breast shielding. Am J Roentgenol. 2008;190(1):W54-W61. doi:10.2214/AJR.07.2017

47. Fricke BL, Donnelly LF, Frush DP, et al. In-plane bismuth breast shields for pediatric CT: effects on radiation dose and image quality using experimental and clinical data. Am J Roentgenol. 2003;180:407-411. doi:10.2214/ajr.180.2.1800407 
48. Hohl C, Wildberger J, Süß C, et al. Radiation dose reduction to breast and thyroid during MDCT: effectiveness of an in-plane bismuth shield. Acta Radiol. 2006;47:562-567. doi:10.1080/02841850600702150

49. Samei E. Pros and cons of organ shielding for CT imaging. Pediatr Radiol. 2014;44:495-500. doi:10.1007/s00247-014-3084-z

\section{Publish your work in this journal}

The Journal of Multidisciplinary Healthcare is an international, peer-reviewed open-access journal that aims to represent and publish research in healthcare areas delivered by practitioners of different disciplines. This includes studies and reviews conducted by multidisciplinary teams as well as research which evaluates the results or conduct of such teams or healthcare processes in general. The journal covers a very wide range of areas and welcomes submissions from practitioners at all levels, from all over the world. The manuscript management system is completely online and includes a very quick and fair peer-review system. Visit http://www.dovepress.com/testimonials.php to read real quotes from published authors.

Submit your manuscript here: https://www.dovepress.com/journal-of-inflammation-research-journal 